\title{
Sergey Hessen's Philosophy of Education
}

\author{
Igor Grebeshev \\ Department History of Philosophy \\ Peoples' Friendship University of Russia \\ Miklukho-Maklay str., 10/2, Moscow, Russia, 117198 \\ E-mail: igor.grebeshev@yandex.ru
}

\author{
Sergey Nizhnikov \\ Department History of Philosophy \\ Peoples' Friendship University of Russia \\ Miklukho-Maklay str., 10/2, Moscow, Russia, 117198 \\ E-mail:nizhnikovs@mail.ru
}

\begin{abstract}
The article considers the project of Sergey Hessen's Philosophy of Education, addressed in the context of the thinker's general philosophical views, which had been influenced by the European neo-Kantianism tradition. However, Hessen argued (in line with Russian personalist metaphysics) that "identity is acquired only through the work on super-personal objectives". In contrast to analytic philosophy, pedagogical anthropology and "dialogical philosophy" (M.Buber), Hessen's standing is closer to the type of philosophy of education, emerged from the Humanities.
\end{abstract}

Keywords-Kantianism; education of the person; University education; Philosophy of education; personalism; educational tradition; moral education

\section{INTRODUCTION}

Sergey I. Hessen (1887-1950) noted in his "The Foundations of Pedagogy" (1923) that "the power of individuality is rooted not in itself nor in the natural power of its psycho-physical organism but in those spiritual values which imbue the body and soul...". In addition to the physical and mental, he recognizes "the third kingdom" of "values and meaning", although understanding it in neoKantianistic way - transcendental but not transcendent. As Zenkovski notes, Hessen "is constantly on the verge of metaphysics - but only on the verge". The following works of Hessen's are dedicated to the problems of anthropological and metaphysical morals: "Leo Tolstoy as a Thinker", "The Tragedy of Good in "The Brothers Karamazov", "The Struggle of Utopia and Autonomy of Good in World Views of Dostoevsky and Solovyov", "The Tragedy of Evil", and others. S. Hessen developed the concept of "legal socialism", based on a foundation of liberal and democratic values (see "The Legal State and Socialism", 1924) - just in the spirit of social and cultural Kantianism.

Vladimir Solovyov believed Kant's understanding of personality and, in particular, individual's ethical sense to be much more productive than the idea of personality-substance found in pre-critical metaphysics. In his "Good's Excuse", arguing about the "rationality" of moral choice, V.Solovyov largely relied on the general principles of Kant's "practical reason" theory. Worth noting, that V. Solovyov once again proved to be quite insightful concerning the perspectives of philosophical development. In the subsequent Russian neoKantianism, the individualistic line received a distinct ethical orientation. This also fully applies to Hessen's philosophical works, representing the younger generation of the Russian neo-Kantians. A significant part of Hessen's works came in the period of his immigration and was associated primarily with the development of a fundamental system of the philosophy of education. We may say that Kantian ethical individualism played a significant methodological role in philosophical pedagogy of the Russian thinker. The very same theory can currently be useful for a philosophical understanding of the personality in modern cultural and educational processes.

Hessen's philosophy of education may only be understood in the context of the general philosophical views of the thinker who was crucially influenced by the European neo-Kantianism. Upon graduating from the St. Petersburg University's law faculty, S. Hessen received a philosophical education in Germany at the universities of Heidelberg and Freiburg, where he studied under the direction of H. Rickert, W. Windelband and E. Lask. In 1910, he defended the doctoral paper "On personal causation" in Germany. At that time, there was a draft of a new philosophical international magazine among the Russian and European neo-Kantians. The result was "Logos" (1910-1914), in which S. Hessen (along with F. Stepun and B.Yakovenko) played a significant role. Since 1913 till 1917, Hessen was Privatdozent of St. Petersburg University. In 1922, the philosopher leaves Russia. In 1924, he worked at the Russian Pedagogical Institute in Prague. In 1934, he moved to Poland where he lectured at the universities of Warsaw and Lodz. S. Hessen stayed true to the core principles of "critical" philosophy in philosophical anthropology and educational theory ("applied philosophy"), including when insisting that "personality is acquired only through work on the super-personal objectives" [1. P. 73].

\section{Sergey Hessen's Moral EduCATION}

S. Hessen's philosophy of education may appropriately be appreciated in the light of the fundamental principles of his general philosophical methodology. Hessen strongly defended the universal principle of education's function regarding civilization. According to his theory, every developed culture consists of three interrelated spheres: education (science, art, morality, and religion), citizenship (law, state) and civilization (economy, technology). The role of "education" is crucial. "There is, thus, an exact match between education and culture. Education is nothing less but the culture of an individual". Cultural-historical meaning 
manifests itself in this personal aspect. Pedagogical systems always deal with the moral, scientific, art, religious and economic education. Different types of utopian ideology are criticized in his book, "The Legal State and Socialism". Hessen stressed the hostility of utopianism towards the cultural-educational traditions. "Maximalism (all or nothing) is a main feature, common to all types of utopianism; the associated sweeping denial of everything historically settled everything inherited from the previous generations". Utopianism's anti-traditional mentality itself provokes nihilism in relation to the existing educational systems and, accordingly, the desire of their revolutionary transformation. The Russian philosopher was able to observe the aforementioned tendencies in the Soviet Russian and Europe. Interestingly enough, S. Hessen directly linked the revolutionary projects of the educational reforms to the utopian radical anti-historicism. In "The Foundations of Pedagogy", he stated that "if educational problems are the cultural problems, than, obviously, the denial of culture, interrelated to the denial of history, leads to the denial of education". Nowadays, we may justifiably note that something similar had actually taken place. Take "The End of History and the Last Man", a popular work by F. Fukuyama, e.g.: "There is neither art, nor philosophy in the post-historical period; there is just a carefully watched-over museum of human history". S. Hessen was a determined opponent of such "museum" models of "the end of history". We may say that he remained a consistent Kantianist in this case, a supporter of the idea of inexhaustibility of culturalhistorical progress of mankind.

Personal existence of an individual is itself the result of a creative choice, individual creative efforts. Natural psychological type, personality is a kind of natural foundation for an individuality which, in turn, is in constant process of becoming, of working on super-personal objectives. Personality and culture exist only in close, constant and organic interaction. The very formation of personality is realized through the participation of an individual in general for mankind cultural construction. Reflecting on "the rootedness of personality in superpersonality", S. Hessen appealed directly to V. Solovyov's metaphysics of morals. For the metaphysics of unity, one is able to become a personality only on the way to the Absolute, or, as V. Solovyov argued, while transforming into "the becoming mind of truth itself". Hessen's position is largely different; "super-personal", for him, is a universal world of Kantian cultural values, where an individual is only able to find and acquire own moral entity. However, it is important, that S. Hessen was one of the few Russian philosophers, who saw in V.Solovyov's later works not only anti-personalism, but the statement of a problem to metaphysically "justify" a human personality in the radically new historical, social and cultural conditions.

Ivan V. Kireyevsky defined two types of education in his article "The Review of the Current State of Literature" (1845): the first one is "the inner dispersion of the spirit by the power of truth present in it", the second one is "the formal development of mind and external knowledge" [4. P. 159]. Education of the second type is only useful when obeying the first one, the "higher" education. If the second type starts to dominate, then it is a symptom of a cultural crisis. The most important part of S. Hessen's philosophy of education is also a theory of inner "moral education". At that level the personalist orientation of the Russian Kantianist finds the most complete and consistent expression. The very task of the moral education is "the formation of personality in an individual". This is the task for, literally, the whole lifespan. Accordingly, "the moral education can't end at a certain period of human life". This is a continuous creative process, involving as a prerequisite a freedom of an individual's moral choice.

According to Hessen's concept, moral education has three stages: anomie, heteronomy, autonomy. Anomie (Greek: "lawlessness") is a stage of moral chaos where the norms absent and "arbitrary existence" presents. An individual at the anomie stage is a fully natural creature obeying the rules of nature. The essence of the heteronomic stage is in the development of legal consciousness and the formation of social relations. An individual becomes a personality at the autonomous stage. At this stage moral education transforms into cultural-historical reality. This we may find in A. Khomyakov's educational concept, where he recognizes two major educational systems of mental education: "training", focused on specialization and "generalization", representing the world and knowledge in entirety, as a whole. Under the second system, a student defines the study subject and reveals personal interest to any science. The "generalization" - or understanding - system, according to A. Khomyakov, is based on the idea of living and whole human mind (as taught by Kireyevsky). Khomyakov wrote: "The goal of mental education is not only to transfer the private knowledge, but also to develop the thinking ability as a whole" [3. P. 233]. Such education is not limited to school at all of its stages. "The last and the superior teacher is the society itself", insisted the Slavophil, warning at the same time about the possibility of lowering the quality of education due to its inevitable mass availability (even the increasing book printing technical capabilities "can be used for evil").

In Hessen's moral education theory, the analogy between historical and individual fate of a person plays an important role. "Everyone passes the three distinguished stages of anomie, heteronomy and autonomy that, in essence, correspond to the three stages of education: pre-school, school and out-of-school". At an individual level, anomie is a stage of childhood, and, without comprehending the peculiarity of anomie stage, one cannot achieve success in pre-school education. According to Hessen, anomic elements manifest themselves clearly during the child's games. Therefore, pre-school education cannot be anything else, but the right organization of a game. A child is the biggest anarchist in the world, recognizing no authorities except the natural power and force. As Hessen emphasizes, "authority is power that we subject not simply by coercion (overt or hidden), but by a voluntary recognition". Accordingly, the teacher's authority is only possible if it is not alien to a child's anarchic anomie.

Considering the problems of child's moral education, Hessen examines the concepts of his contemporary Italian 
educator M. Montessori and of F. Fröbel, F. Schelling's follower. Referring to Fröbel's theory, the Russian thinker highly appreciated Schellengian motives and, particularly, the problem of children's mythological consciousness, the exceptional role of imagination in the child's inner world and behavior. At the same time, Hessen recognized the insufficiency of "abstract idealism" for the philosophical education that shall rely on scientific experience and must take into account "psycho-physiological nature of a child, nature of physicians and naturalists". In this regard we favor Montessori's approach, who succeeded in developing a "scientific system of children's lessons, exercises that shall develop and even refine the senses and motor apparatus of a child". Nevertheless, Hessen sensed some "philosophical one-sidedness" in the Italian positivist educator. Hessen argues quite convincingly that Montessori's the very positivist insights "do not stem, and often even contradict, natural science". The result is "ignoring the child's holistic soul".

In S. Hessen's moral education concept, the heteronomy stage refers to school education. At that human life stage an individual transfers from nature to law, "from natural anomie to the stage of external, social coercion". Worth noting that heteronomical (school) stage, according to Hessen, has no distinct independent value. It is primarily a preparation period for the transfer to autonomy. Therefore, Hessen claimed, "school education should be organized so, that the future purpose of education clearly shines in transition to free self-determination". Even a lesson bears the distinct mark of such "transition": from game to creative work. "Poorly organized lessons" may deform the personality, they "upbring people that know just how to carry out the prescribed purposes, i.e. artisans or officials".

Hessen followed closely contemporary innovations in the field of school education. So, he paid serious attention to different concepts of "labor schools", the more so because, in his opinion, such models appealed to the real needs of "personality forming". From this point of view he reviewed, in particular, theories of labor schools developed by $\mathrm{J}$. Dewey and G. Kerschensteiner, and in Russia, respectively, theories of P.Blonsky and M.Rubinstein. The last two theorists of education were philosophers, just as Hessen was.

\section{PHILOSOPHICAL PRINCIPLES OF SCIENCE EDUCATION}

S. Hessen consistently expressed the essence of his own understanding of philosophy of education. Philosophy, including the philosophy of education, cannot exist and develop without relying to the real ("not in the sense of an arbitrary product of imagination") power of ideas, ideals, principles, universal values, moral and legal requirements. We may speak of a principle of "lifelong education", clearly formulated by the Russian Kantianist. After completing the school education, an individual enters "the period of wandering", continues to strive for self-determination "in the world of spirit and culture". School turns out to be a foundation upon which an individual could become a true subject of physical and, above all, cultural space.
Hessen's idea of "lifelong education" as some kind of "wandering" in the world of culture, upon his own remark, has nothing to do with "idle tourism". Self-education implies "selfless work" and, of course, understood and acknowledged on a deeply personal level the (Kantian) ethics of duty. In comparison to the school stage, the studying "wanderer" acquires autonomy and acts outside the rigid boundaries of educational program. Ultimately, both success and failure of self-education depend solely on the student. In Hessen's philosophy of education, the stage of "free self-education" is essentially the highest stage of moral education. The moral paradigm defines the style and direction of educational searches, profoundly affecting the nature and content of "science education".

In his philosophical pedagogy, the thinker systematically explored the principles of moral, law and scientific education All these education types both in theory and in practice have, according to S. Hessen, a very high degree of autonomy. So, e.g., moral education is implemented at every stage of education and never loses its connection to the science education. In his work "The Struggle of Utopia and Autonomy of Good in World Views of Dostoevsky and Solovyov" (1929), S. Hessen solved the problem of the metaphysics of morals that had a significant role in his philosophy of education. The thinker analyzed the problems of interconnection of moral and religious ideas, the role of theoretical knowledge in an individual's moral choice, dialectic of various forms of freedom and lack thereof in cultural-historical experience of mankind and in the individual's experience. We may argue that considering the spiritual journey of F. Dostoevsky and V. Solovyov, S.Hessen sought and found in it a confirmation of the possibility of a real synthesis of the moral and philosophical (metaphysical) experience; synthesis was crucial to solving the problem of upbringing and educating an individual.

Of special interest for understanding the essence of $\mathrm{S}$. Hessen's personalist philosophy, it is his consistent apology of the Humanities, primarily regarding history. The Russian philosopher was convinced that naturalistic monism will never be able to "erase" the humanity's interest for history, interest for "individualism" as the subject of history. We have already mentioned that Hessen, like many other European and Russian thinkers before him, considered educational, scientific and philosophical interest to be a fundamental feature of human nature. The Humanities' anthropological nature is unquestionable and that serves as a possibility for its metaphysical justification. S.Hessen strived to prove that historical (humanitarian) knowledge may as much be "useful", as the natural science. To illustrate such "usefulness", he refers to the experience of the French revolution. In fact, its leaders were rationalists and adherents of the "natural law" philosophy, convinced of the utter primacy of the "general" laws of natural and social lives. They "ignored individuality of their people" and were going to build a "new world" out of nowhere in a vacant place. According to Hessen, "the rejected history" had its last cruel laugh on the revolutionaries and used them "as proxies for its own purposes". 
At the same time, Hessen believed that the reformation of history (in certain historical moments) is possible and necessary. But the general historical pattern scheming is insufficient for that purpose. Of fundamental importance are the understanding of the "individual state of society" and knowledge of "substantially specific" features of society's existence. Without such concrete historical knowledge any historical "alignment" is destined to fail. Hessen's position allows us to determine some fundamental aspects of the modern-day Russian reformation experience. It is the lack of reformers' understanding of specific ("individual") features of the social and economical situations in Russia and the world to blame for the negative outcome of the 1990s reforms. Politician's greatest art, claimed Hessen, is in the ability to limit his own will according to the individual and unique situation to which it should have been applied. Hessen believed this art is brought up mostly through historical thinking. The deficit of historical thinking in the modern Russian politics certainly played a negative historical part.

The question of place and role of philosophy in the Humanities was of a particular importance to the Russian philosopher. He disagreed strongly with the positivists, who, in fact, reduced philosophy to "the servant of natural science". The subject of philosophy, according to S.Hessen, is to explore the meaning and significance "of those value assignments that together constitute the mankind's culture". These kind of "meanings" may be perceived unconsciously outside the philosophy. So, an artist is guided by his intuition of beauty, a scientist, using the scientific apparatus. However, they may make mistakes in his understanding of science, "uncritically repeating the floating philosophical prejudices" (the famous Baconian "philosophical theater"). Philosophy, according to Hessen, is a critical reflection in relation to what is intuitively and unconsciously familiar to every person involved in cultural work. Philosophy, in this sense, is the highest form of humanitarian rationality, experience of self-perception, knowledge of self in humanity, "meaning by the latter not biological-psychological existence, but the corpus emerging in an individual's soul creative tasks". Practical application of philosophy as theoretical knowledge is a pedagogy, solving an individual's problem of formation and development.

In S. Hessen's personalist philosophy of education, an original pluralistic classification of scientific knowledge is presented. The philosopher identified five broad academic disciplines: natural science, mathematics, history, philology and philosophy. These disciplines correspond to the three most fundamental areas of cognition: mathematical cognition of an "exemplary" (H. Rickert) reality; linguistic cognition of an "individual" reality; "dialectical cognition of the meanings of important values". Each of these areas has a special type of scientific concept: the concept of law, the individual concept, and the concept-idea. The classification of knowledge has a definite pedagogical sense. "First of all, from the defined classification of sciences follows that all five academic disciplines should be represented in a general science education. Scientifically developed individual is the one who got in touch with all these disciplines and absorbed tolerance and ability to appreciate mankind's scientific work in its diversity". Hessen identifies three stages of science education: episodic (introductory), systematic and scientific (university).

\section{SigNIFICANCE AND AIM OF UNIVERSITY EDUCATION}

S. Hessen's concept of university education serves as a kind of personalist apotheosis of his philosophy of education. On this "highest" step of science education, the opportunity arises to actually implement the principle of unity of lecturing and research. The lecturer and the student not only lecture or study, but also do science, and education thereby coincides with an individual research activities. "University is the realization of science itself...", - asserted Hessen, considering the university education "the ideal of a free lecturing and studying". Just as Schelling and Humboldt before him, Hessen believed that a university professor is not required to have a special pedagogical education; ultimately, all higher educational didactic methods are subordinated to the task of understanding scientific knowledge. Teaching methods of any science course not only rest on the methodology of the relevant science, but "downright coincide with it". Therefore, stressed the philosopher, it is fair that "the fitting of the professor to auditorium does not improve the lecturing but actually hurts it, robbing the professor of the nature of scientific research". The subordination of the professors to the didacticmethodological requirements contradicts the very spirit of university education and may, therefore, be fatal for it. The university professor is foremost a leading scientist, an expert in his particular discipline. In fact, the only pedagogical goal is to introduce a student into the world of the highest achievements and the most acute scientific problems.

Extremely relevant, to our opinion, is S. Hessen's conceptual characteristic of the meaning and significance of a university lecture. The role of a lecture course in the university education cannot be overestimated. The philosopher argued that a lecture is not just a traditional form of education, but the most important integral element of the university education: "to abolish a lecture is to abolish a university". Hessen recognized that critical remarks towards the lecture system are not entirely causeless: the students' passivity during the lectures, non-attendance, the students' use of textbooks and not the actual lecture materials, etc. But, according to the Russian thinker, such criticism itself is an evidence of the decline of the scientific spirit in the University, which may lead to the actual "degeneration of the lectures into the simple presentation of certain information". The opponents of the lecturing tradition are "the children of crisis", exhibiting a complete misunderstanding of lecture's real meaning, which, as Hessen proved, "is in revival" of students' pro-active attitude towards science and in the formation of their desire to study themselves, using the lecture material "in order to independently verify the conclusions of their professor". Therefore, a lecture has a positive provocative meaning, provoking a student to look for his own path in science.

Of course, the lecture itself is not a panacea. Moreover, it can also have a completely opposite effect. The more 
important the professor, the stronger and deeper his problems' development during the lecture, the more real, to $\mathrm{S}$. Hessen, is a danger for students to become literally overwhelmed by the greatness of intellect and knowledge, to be pushed to the background of "the authorities' game", "the philosophical theater", that was once predicted by F. Bacon. But the university tradition, noted the Russian philosopher, had already found a way out of that situation. Practical (seminar) classes reduce the distance between chair and audience. Collaboration, genuine dialogue among the students and a professor, are essential for maintaining the University spirit of creative research.

The University concept is one of the central and the most striking ideas of S. Hessen's philosophical-educational system. Only at the university the ideal of free education may be realized. Not only university professors are entitled to creative organization of the educational process. No less important is the students' freedom. We may say that in this case the philosopher directly foresaw certain trends of modern-day university education.

Consistently defending the principles of free university education, S. Hessen was, at the same time, critically inclined towards any manifestations of anarchy in universities. He strongly believed that the anarchic freedom easily "degenerates into tyranny, and, instead of the spirit of philosophical studies, cultivates a superficial dilettantism". This kind of anarchic dilettantism has nothing to do with the university's "spirit of freedom". The role of the university as "a kiln of knowledge", according to Hessen, presupposes autonomy of university education and self-government. "The three mentioned principles - completeness of scientific knowledge, freedom of teaching and learning, selfgovernment - characterize an ideal essence of the university as a kiln of scientific knowledge, ensuring the continuity of scientific creativity through the management of lecturing and providing science education through the introduction of the students to research" [1. P. 316]. Defining the essence of university education, Hessen considered an ideal model of the university. In the history of culture, according to him, "the ideal university principles find either more or less full expression". The philosopher foresaw that internal and external communications among the universities will develop while undoubtedly preserving the autonomous state. Only in this case the university's scientific community may effectively fulfill its cultural mission of being the "supreme guardian of the scientific tradition".

In S. Hessen's concept we find a philosophical analysis of all stages and types of education, from pre-school to university. Consistently and systematically, the following main characteristics of complex educational tasks are represented in his theory: moral, law and science. Guided by the idea of the fundamental importance of the philosophical foundations of education, S. Hessen conceptually based the philosophical nature of pedagogical knowledge and experience. Organic unity of philosophy and education is, in fact, ("in the last essence"), determined by rational reasons ("logic of philosophy"). In the solution of educational and upbringing tasks, philosophy finds its specific fields of application and, to Hessen, philosophical experience.
Philosophy is extremely useful when solving problems arising at the intersection of educational theory and practice with political and ideological values. Hessen, in this regard addresses the question of the "national education". As the philosopher noted, this motto was used in different historical periods by a number of political trends: radical revolutionists, conservatives, nationalists, statists, supporters and adversaries of federalism. Hessen remembers $M$. Robespierre, E. Lepelletier, J. Fichte, M. Katkov, D. Tolstoy and others. One of the most conceptual projects of the "national school" was, according to Hessen, philosophicalpedagogical theory of Konstantin Dmitriyevich Ushinsky (1823-1870). As V.V. Zenkovsky pointed out, Ushinsky's works "astound with a huge psychological talent of the author, the wealth of new designs and methods, the accuracy of the methodology, the exceptional breadth of knowledge and harmony of the whole plan" [7. P. 70].

Dynamics of "national life" has never fit into any nationalist scheme. The philosopher insisted that the nation itself cannot be self-sufficing and supreme principle, as the absolute of the national values (even the most real and remarkable) leads eventually to disintegration and loss of identity: "A nation that has placed itself as an ultimate goal of its existence, undergoes the fate of an individual putting nothingness at the basis of self: it falls apart" [1. P. 342]. S. Hessen emphasized, the spirit of people doesn't give birth to a cultural tradition by itself - this requires supreme and absolute values.

Indicative to the Russian metaphysics in general is the pathos of vitality of philosophical creativity that fully manifests itself in S. Hessen's philosophy of education. The thinker was convinced that philosophy is tied to life through a world view - a unified vision of the world, based on axiological judgments. In one of his later works, "On Contradictions and Unity in Education" (1939), he stated that philosophical creativity helps to overcome "determinism" of historical and social life conditions, advances an individual to the transcendent world of objective values. "Transcending personality" is an "overarching goal" of philosophical pedagogy, when life is directly related to the "super-personal values". This axiological connection lends vitality to world view and keeps it from turning into ideology or "dead" abstract knowledge [2].

S. Hessen planned to complete his philosophical pedagogy experience by constructing the philosophical system of education. His last book, "The Philosophy of Education", was dedicated exactly to the solution of that problem. The book was being created under the tragic circumstances of Nazi occupation of Poland. Unfortunately, "the manuscripts still burn". Fully prepared for printing, the book was burned during the Warsaw uprising in 1944 . We can judge the content and the main ideas of the book only on the summary found in Hessen's memoirs. "The Philosophy of Education" consisted of four parts: 1. upbringing as a biological process; 2 . education as a social process; 3 . education as a spiritual process; 4 . education as salvation. By the author's own testimony, the problem of the "successive ascension" in educational theory was methodologically solved by transitioning from simple to complex forms and 
from psychology to spirituality and religion. The unity of upbringing and education was seen as a necessary condition for any genuine education in P. Redkin's philosophical anthropology. "To educate" a human being is to "develop his nature so that he can achieve his purpose" [5. P. 71].

S. Hessen was not the only Russian philosopher who, after the Revolution, experienced the world view evolution from the ideals of a strictly scientific philosophy to religiousmetaphysical ideas. In particular, this relates to the late views of A. Vvedensky and the founder of the Russian school of philosophy of law P. Novgorodtsev. F. Stepun, one of the closest people to S. Hessen and his colleague at "Logos", wrote frankly about his quest to find "religious-mystical supplement to transcendental philosophy" [6. P. 126].

In the history of Russian thought, S. Hessen's philosophy of education is a unique phenomenon. In fact, there is no other example of such a profound systematical experience of philosophical foundation of pedagogical theory and practice. On the other hand, we recognize that Hessen's very theory was the result of intellectual discussions, held in Russia for over a century, about the meaning and objectives of education. In "The Foundations of Pedagogy" and several other works, the philosopher per se characterizes basic principles and positions of the discussions participants. Thus, we may say, Hessen was the first one to study pedagogical issues in the history of the Russian philosophy.

Sure, it would be wrong to ignore the role of neoKantianism (especially the Baden school) as the source of S. Hessen's philosophy of education. The philosopher himself never hid the fact that he considered the key "critical philosophy" ideas (from Kant to Rickert) extremely valuable, with regard building up the theory of education. Probably, of the greatest interest was the philosophical-pedagogical experience of P.Natorp, who suggested at time the concept of "social pedagogy". But Natorp's pedagogical works ("Social Pedagogy", 1898; "Plato's Republic and the Idea of Social Pedagogy", 1898; "Pestalozzi", 1909 etc.) were, in fact, dedicated to cultural-historical meaning and "social" objectives of education ("transformation of state and society must start with education") and to the "autonomy of spirit" ("the central council of spiritual work" - Kantian-liberal modification of Plato's philosopher-kings). S. Hessen praised Natorp's philosophical-pedagogical project, although Hessen's contribution to the philosophy of education is enormously greater.

\section{CONCLUSION}

Sure, S. Hessen's philosophy of education is not limited to its real ties to kantian methodology. The Russian thinker also relied on the ideas of the philosophers that were far enough from Kantianism (in particular, on W. Dilthey, J. Dewey, V. Solovyov and some others). But even in this case, we may say that Hessen was quite original in solving the basic problems: the interpretation of pedagogy as principally autonomous sphere of philosophy ("applied philosophy"); the building of a "dynamic" model of education, suggests diachronic and synchronic unity of purpose and educational forms at each stage (anomie, heterogeny, autonomy). They are deemed largely innovative and faithful to classical models of the University theory.

Philosophies of education institutionalization and its allocation to a special area of philosophy is gaining momentum in the mid-twentieth century. We may argue that, to some extent, S. Hessen's philosophical-pedagogical research anticipated that process. Many of his ideas are still relevant. In particular, that can be said about his philosophical critique of various types of educational "nihilism". In recent decades the model of "de-secularization of society" (I. Illich, P. Freire etc.) enjoys a certain influence, actually setting the task of abandoning the traditional education forms (from school to university) under the banner of the struggle against conformism and "totalitarian" pedagogy. In fact, similar principles may be found in the mainstream "postmodern" philosophy, where the emphasis is put on criticism of the role of fundamental sciences and theoretical knowledge in the educational system, a "freedom of expression" and the right to pedagogical experiments are cultivated. (W. Doll, W. Fischer, D. Lenzen etc.). As we have shown before, S. Hessen has always been consistently critical towards such trends in pedagogy (their novelty is problematic in itself): critique of concepts of "free education", "free school community", anarchy, and so on. The Russian thinker proved (we'd like to hope that once and for all) that the philosophical analysis allows to reveal a theoretical inconsistency and the cultural futility of this kind of teaching "alternatives".

Modern philosophy of education is diverse mainly because of the variety of represented philosophical schools: from the exceptionally influential analytical school (R. Peters, I. Scheffler, E. Macmillan, W. Brezinka) to pedagogical anthropology (naturalistic and phenomenological versions) and "dialogical philosophy" (M. Buber). Hessen's position was closer to the type of pedagogy that forms within the framework of humanities in contemporary philosophy of education.

\section{REFERENCES}

[1] S.I. Hessen, The Foundations of Pedagogy. Introduction to Working Philosophy. M., 1995.

[2] S.I. Hessen, O sprzectnosciach I jednoski wychowania. Warszawa. 1939, pp. 67-74.

[3] A.S. Khomyakov, "On public upbringing in Russia," // On old and new. Moscow: Sovremennik Publisher, 1988, pp. 221-239.

[4] I.V. Kireyevsky, Complete collection of works. Vol. 1-2. Moscow: Imperatorskago Moskovskago Universiteta Publisher, 1911.

[5] P.G. Redkin, Selected pedagogic works. Moscow: Ministerstvo prosvyashcheniya RSFSR Publisher, 1958.

[6] F.A. Stepun, "In memory of S.I. Hessen,” Noviy zhurnal. 1951. № 35.

[7] V.V. Zenkovski, Russian pedagogy in XX c. Paris: Religioznopedagogicheskogo kabineta pri Pravoslavnom Bogoslovskom institute in Paris Publisher, 1960. 